\title{
How to be a teleologist about epistemic reasons
}

\section{Forthcoming in Reasons for Belief, edited by A. Reisner and A. Steglich- Petersen, Cambridge University Press}

\author{
ASBJøRN STEGLICH-PETERSEN \\ DEPARTMENT OF PHILOSOPHY \\ UNIVERSITY OF AARHUS
}

\section{Introduction}

According to the teleological conception, reasons are value based. Whether someone has reason to $\phi$ depends on the value of the result of $\phi$-ing, or the intrinsic value of $\phi$-ing itself (Scanlon 1998: 84). Accordingly, on the teleological conception of reasons for belief, whether someone has reason to believe some particular proposition $\mathrm{p}$ on some particular occasion, depends on the value of the result of believing $\mathrm{p}$, or the intrinsic value of believing $\mathrm{p}$, on that occasion. Although this basic tenet of the teleological account of reasons for belief has seemed plausible to many, and a number of attempts have been made at fleshing it out in detail, it remains controversial whether it can be made to work. ${ }^{1}$

We can distinguish between two distinct challenges, or broad categories of challenges, for the teleological conception of reasons for belief. On the one hand, there is the problem of explaining why, on the teleological account, one couldn't have reason to believe a proposition that is not supported by evidence. If reasons for belief are reasons that obtain in virtue of the value of the relevant belief, why does the pleasantness (or some other non-epistemic property of value) of believing a particular

\footnotetext{
${ }^{1}$ For prominent examples, see Bonjour (1985), Foley (1987), Lehrer (1990), Goldman (1999), Lynch (2004), Alston (2005).
} 
proposition not provide a reason for holding it? There are those, of course, who accept the possibility of such non-epistemic reasons for belief. ${ }^{2}$ But many teleologists about reasons for belief wish to maintain that one can have reason to believe a proposition only insofar as the belief is evidentially supported, or has some other epistemic property, depending on the specific account. We can call this 'the exclusivity problem' for teleologists. The problem is that of explaining why only certain properties of value, namely the epistemic ones, can count in favour of beliefs, if reasons are generally a matter of the relevant actions or attitudes resulting in or promoting something of value. I have argued in previous papers that a teleological conception of reasons for belief is compatible with there only being epistemic reasons for belief, and I shall simply assume in the following that this is the case. ${ }^{3}$

The second major challenge for the teleological account concerns the nature of epistemic reasons specifically, regardless of whether such reasons are somehow privileged in supporting beliefs. The problem is that of explaining how epistemic reasons could be value-based in the first place. If epistemic reasons for belief are reasons that obtain in virtue of the epistemic properties of the beliefs that they support, a teleological conception must explain epistemic reasons in terms of the value, whether intrinsic or derived, of those epistemic properties. But as witnessed by the latest decades of theorising about this question, it is all but clear how or why epistemic properties are valuable or conducive to something of value, in a sense that is sufficiently general to form the basis of a teleological account of epistemic

\footnotetext{
${ }^{2}$ See Reisner (2008) and (2009) for a recent discussion and defence of the idea of non-epistemic reasons for belief.

${ }^{3}$ See Steglich-Petersen (2006a), (2006b), and (2009).
} 
reasons. ${ }^{4}$ This is the challenge I address in this paper. In the following, I shall call it 'the value problem' for teleological accounts of epistemic reasons. ${ }^{5}$

The most common approach to the value problem accepts the basic premise of the challenge, namely that if the teleological account is to succeed, epistemic properties must somehow be of value, or be conducive to something of value, in some general sense. Accordingly, the common approach attempts to solve the problem by locating the epistemic properties of value, and explaining the sense in which they are valuable. A candidate account might hold, for example, that true beliefs are of intrinsic value, and that any property of beliefs that ensures or makes it likely that a belief is true (such as the property of being evidential supported or being the result of a reliable mechanism) therefore is valuable as well. ${ }^{6}$ However, in spite of intensive efforts, this strategy has not yet reached a widely accepted solution.

In this paper, I explore the prospects of a slightly different strategy in solving the value problem for the teleological account of epistemic reasons. The starting point of the strategy is to concede the main criticism of teleological accounts of epistemic reasons, namely that epistemic properties (whatever the relevant epistemic properties might be) are not valuable generally and in all contexts, and that a teleological account relying on such a claim therefore fails. So the question becomes if a teleological explanation of epistemic reasons, which doesn't rely on that claim, is available. I will introduce and motivate such an account.

At the core of the account lies a distinction between two different kinds of reasons concerning beliefs, namely reasons to form beliefs that particular propositions

\footnotetext{
${ }^{4}$ For a recent discussion of representative proponents of this line of explanation, see Grimm (2008).

${ }^{5}$ The value problem for a teleological account of epistemic reasons is distinct from several other socalled 'value problems' in epistemology, most notably the problem of explaining the value of knowledge as opposed to mere true belief. For a survey of recent work on this problem, see Pritchard (2007).

${ }^{6}$ For this particular account, see Lynch (2004).
} 
are true, i.e. epistemic reasons, and reasons to form beliefs about certain propositions or subject matters. I shall argue that the latter kind of reasons is connected to value in a straightforward way: whether one has reason to form beliefs about some proposition or subject matter is determined by the value of doing so, in the same way reasons for actions seem determined by the intrinsic or derived value of those actions. I shall argue further that the two kinds of reasons stand in a certain systematic relationship to each other that any theory of those reasons must explain. To anticipate, epistemic reasons to believe that $\mathrm{p}$ entail that one ought to believe that $\mathrm{p}$ only in the context of an all things considered reason to form a belief about $\mathrm{p}$. I then go on to provide a teleological account of this relationship. I shall argue that the relationship can be explained by supposing that having an epistemic reason to believe that $\mathrm{p}$ is equivalent to having what I term a 'hypothetical instrumental reason'. The main virtue of the account is that it does not require the epistemic properties underlying epistemic reasons to be of value in all contexts. Only if one has reason to form beliefs about the relevant subject matter do epistemic properties of some potential belief about that subject matter become valuable, and since one can have epistemic reason to believe some proposition without having reason to form beliefs about that proposition, epistemic reasons can obtain without the epistemic properties in question being of value.

\section{Definitions}

To fix matters, it will be useful to begin by clarifying what I shall mean by a number of central notions. First of all, we need to clarify the notion of a 'reason'. By a 'reason', I shall mean a fact or consideration that stands in a reason-giving relation to some particular action or attitude of some particular agent (Scanlon 1998: 17). The 
reason-giving relation can take different forms, depending on the kind of reason.

Generally, the relation is that of favouring the relevant action or attitude, so a reason to $\phi$ is something that somehow favours $\phi$-ing. But there are different kinds or 'grades' of favouring. Some reasons may by themselves require $\phi$-ing, i.e. make it the case that one ought to $\phi$. Such reasons are sometimes called 'perfect reasons' (Broome 2004), but I shall instead call them 'all things considered reasons'. Other reasons may favour $\phi$-ing in a mere 'pro tanto' way. Such reasons can usefully be thought of as considerations that can play a role in a weighing-explanation of what one ought to do, where the weight of several pro tanto reasons are compared to reach a judgment about what one overall ought to do in a given situation (Broome 2004). So having a pro tanto reason to $\phi$ does not necessarily entail that one ought to $\phi$. There might be other pro tanto reasons not to $\phi$, or to do something else that excludes $\phi$-ing, which weigh heavier than one's reason to $\phi$. This being said, the distinction between all things considered reasons and pro tanto reasons should not be understood to sharply. Sometimes a pro tanto reason to $\phi$ by itself make it the case that one ought to $\phi$ - for example in case there are no opposing reasons not to $\phi$. In that case, the pro tanto reason to $\phi$ is an all things considered reason as well. Moreover, what we treat as all things considered reasons are often in fact the result of weighing several pro tanto reasons for and against the relevant action. The distinction is thus somewhat blurry, and I agree with those who regard the notion of all things considered reasons as derivative of the notion of pro tanto reasons (Broome 2004). Nevertheless, the distinction is useful. $^{7}$

\footnotetext{
${ }^{7}$ Some have suggested that there are reasons that merely 'entice', i.e. make it the case that $\phi$-ing would be attractive for the agent, without thereby implying that the agent would commit a mistake or otherwise be in the wrong if he fails to respond to it (Dancy 2004). For a discussion relating these different kinds of reasons to evidence, see Steglich-Petersen (2008b).
} 
For reasons that will emerge later in the paper, it will be useful to represent these relationships between reasons and corresponding oughts-statements as conditionals, having reason-statements as antecedents and statements about what an agent ought to do in the appropriate sense as consequents:

Necessarily, if S has all things considered reason to $\phi$, then $\mathrm{S}$ ought to $\phi{ }^{8}$

Necessarily, if S has pro tanto reason to $\phi$, then, in the absence of opposing reasons, S ought to $\phi$.

Different kinds of reasons can thus be distinguished, at least in part, by the kinds of ought-statements they entail. In investigating a class of reasons, part of what we are interested in is the kind of ought-statement entailed by that class of reasons, i.e. in what sense the reason in question favours the relevant action or attitude. As the case of pro tanto reasons shows, reasons do not always entail unqualified oughts, but only more complex or conditional statements including oughts. This shall become important later on when investigating the nature of epistemic reasons, where it is all but clear in what sense they favour or make it the case that one ought to form the relevant belief.

Although the teleological account of reasons might be committed to certain characteristics of the favouring relation that reasons can stand in, ${ }^{9}$ it is primarily an account of another aspect of reasons, namely of the kinds of considerations or facts

\footnotetext{
${ }^{8}$ 'Necessarily' indicates that the relevant conditional is that of entailment rather than a contingent relation. Whenever not explicitly mentioned otherwise, I shall take 'if' to stand for the material conditional.

${ }^{9}$ For example, it is sometimes argued that teleological accounts of reasons are committed to the view that all reasons can be compared and weighed against each other. For this view, see in particular Joseph Raz (1986).
} 
that are able to constitute reasons, and thus stand in the favouring relation to actions or attitudes in the first place. According to the teleological account, some fact or consideration can be reason for an action or attitude only in virtue of being a fact or consideration about the value, intrinsic or derived, of the action or attitude that it favours. For example, the fact that an action promotes wellbeing is a reason to perform it, since wellbeing is valuable.

Finally, by 'epistemic reasons', I shall refer to considerations that count in favour of holding a belief in a particular proposition solely on account of that (potential) belief's epistemic properties. In this paper I wish to remain neutral on the exact nature of the epistemic properties giving rise to epistemic reasons, but by 'epistemic properties' I shall generally mean properties that are in some way relevant to whether or not the proposition believed is true. On this very general definition, being evidentially supported is the most obvious candidate for an epistemic property, but I shall not exclude other candidates in advance.

\section{Epistemic reasons and value}

With this rough characterisation of reasons, and the teleological account of these, we can go on to consider the teleological account of epistemic reasons specifically. According to the common version of this account, epistemic reasons for beliefs obtain in virtue of the value, either intrinsic or instrumental, of the epistemic properties of the beliefs they support. When I have an epistemic reason for a particular belief, the belief must have some epistemic property that somehow constitutes or promotes something of value. On the teleological account, epistemic reasons thus share an important characteristic with practical reasons: they both support actions or attitudes in virtue of those actions or attitudes promoting or 
constituting something of value. What distinguishes epistemic reasons is that the valuable property of beliefs, which the reason is based on, is an epistemic property, such as being true, supported by evidence, etc., depending on the specific teleological account. This means that the teleologian must explain why those epistemic properties are valuable or promote something of value.

Critics often point out that beliefs supported by epistemic reasons do not thereby become valuable or come to promote something of value. If epistemic reasons for beliefs are reasons that obtain in virtue of the relevant beliefs having some epistemic property that is of value or promotes something of value, then all beliefs supported by epistemic reasons must be valuable or value promoting. But not all beliefs supported by epistemic reasons are valuable or value promoting. In fact, some beliefs are just the opposite, despite being supported by epistemic reasons. Numerous examples of such beliefs have been given in the literature. Most of them invoke propositional contents that it would be trivial or even harmful to form beliefs about, but are nonetheless supported by epistemic reasons. To give but a few recent examples: Thomas Kelly (2003) asks us to imagine being about to watch a suspense thriller. In that case, most of us would prefer not having epistemically supported beliefs about the ending of the movie, since our enjoyment of it hinges at least in part on not knowing the ending. Alvin Goldman (1999) and Stephen Grimm (2008) offer several examples of propositions that it wouldn't be outright value-detracting, but nevertheless worthless to form beliefs about: What is the $323^{\text {rd }}$ entry in the Wichita, Kansas phone directory? Is there an even number of dust specks on my desk? Such cases seem to show that epistemic reasons for beliefs do not depend on the value of those beliefs. A belief can be true, justified, warranted, supported by evidence, etc., without thereby becoming either intrinsically valuable, or conducive to something of 
intrinsic value. A world in which I have a true, warranted belief about the number of dust specks on my desk is not better than a world in which I have no such belief. A world in which I have a true, warranted belief about the ending of a suspense-thriller I am about to watch is actively worse, certainly from the perspective of my own aims, but arguably also intrinsically, than a world in which I have no such belief. Epistemic evaluation of beliefs thus seems entirely independent from questions of value.

It may well seem fantastic to claim that epistemic reasons do not depend on the value of the beliefs that they support. Surely, a warranted belief is more valuable than an unwarranted one; surely, a true belief is more valuable than a false one. But if the above criticism of the teleological account is sound, that is the conclusion we are driven to accept. Although it often is the case that a warranted belief is valuable, no general claim of that sort seems available. It is always possible to find counterexamples involving epistemically supported beliefs in very trivial propositions, or propositions that the believer would be better off not having beliefs about. $^{10}$

There are two common strategies for averting this objection against the teleological account. Some defenders of the teleological account have tried to avert it by attempting to show that epistemic reasons, despite appearances, $d o$ indicate that the relevant beliefs are somehow valuable. Michael Lynch (2004) insists, for example, that epistemically well-founded beliefs (in his case, true beliefs), about even extremely trivial or inconsequential matters are valuable, since we value truth in its own right. The main problem with this view is that it seems implausible to claim it worthwhile or valuable to form beliefs about trivial matters such as those mentioned

\footnotetext{
${ }^{10}$ Something not often noted is that the value-independence of epistemic reasons, if true, would be just as puzzling for non-teleological accounts. How can any reason, let alone teleological ones, be entirely independent of value? Some have suggested that reasons for belief are instead generated by a special constitutive non-teleological norm governing belief (Shah 2003; Shah and Velleman 2005). For criticism of this view, see Steglich-Petersen (2006a; 2008a).
} 
above. Others teleologians recognise that some epistemically well-founded beliefs aren't valuable, but attempt to salvage the teleological account by restricting epistemic reasons to support beliefs that are of interest. ${ }^{11}$ But this strategy undermines the basic tenet of the teleological explanation of epistemic reasons. If epistemic reasons obtain in virtue of the relevant beliefs having valuable epistemic properties, then beliefs without valuable epistemic properties cannot be supported by epistemic reasons. But it seems that even extremely trivial and uninteresting beliefs can be supported by epistemic reasons. However uninteresting, it is possible to have an epistemically well-supported belief that there is an even number of dust specks on my desk. Although I cannot argue for this claim in full here, it thus seems that both common strategies in salvaging the teleological account are in trouble. ${ }^{12} 13$

In the following, I propose to accept that epistemic reasons can obtain independently of the value, whether intrinsic or derived, of the beliefs that they support. My belief that the suspense-thriller I am about to watch ends in a particular way can be epistemically unassailable, entirely underwritten by epistemic reason, even if it would be better from a value perspective if I hadn't had that belief. Likewise, my belief that there is an even number of dust specks on my desk can be well-supported by epistemic reasons, even if nothing of value would be promoted by forming such a belief. Nevertheless, I will argue that there is a broadly teleological account compatible with these claims.

\section{Two kinds of reasons for belief}

\footnotetext{
${ }^{11}$ This strategy is adopted by, for example, Goldman (1999) and Alston (2004).

${ }^{12}$ For a more thorough recent criticism of these two strategies along the same lines, see Grimm (2008).

${ }^{13}$ If epistemic and practical values could be weighed against each other, these problems would have an easy solution: in all of the mentioned cases, the epistemic value of the relevant belief is outweighed by some competing practical value. It is doubtful, however, whether such weighing is possible. For further discussion, see Reisner (2008) and Steglich-Petersen (2009).
} 
Normally, reasons for belief are taken to be reasons for believing that some particular proposition, or body of propositions, is true. But this is not the only kind of reasons relating to beliefs. Another important class of reasons for belief are the reasons we might have to form or have beliefs about particular propositions, or sets of propositions. When one has reason to form a belief about some proposition $\mathrm{p}$, one has reason to form a belief as to whether $\mathrm{p}$ is true or not. These two kinds of reasons are clearly independent of each other in the sense that neither entails the other in regard to some particular proposition. Having reason to form a belief about or as to whether $\mathrm{p}$ does not entail having a reason to believe that $\mathrm{p}$, nor vice versa. I can have reason to form a belief as to whether the Americans landed a man on the Moon, without having reason to believe that they did in fact land a man on the Moon. For example, I might expect to be met with that question in a quiz, but not yet have any evidence concerning it. On the other hand, I can have reason to believe that there is an even number of dist specs on my desk (in the sense of having the relevant evidence), without thereby having any reason to form a belief about that proposition. I might be completely uninterested in the matter, and with good reason.

The notion of reasons to form beliefs about propositions or subject matters is in some respects similar to the notion of having a reason to engage in inquiry, i.e. a reason to actively pursue evidence bearing on a certain proposition or subject matter. There are important differences, however. For one thing, reasons to form beliefs about propositions are more general than reasons to engage in inquiry in regard to those propositions. It may be that reasons of the former kind entail reasons of the latter kind, i.e. that one has reason to engage in inquiry about some subject matter whenever one has reason to form beliefs about it. But that does not make them identical. Another reason to not simply treat them as identical is that doing so would exclude in 
advance the possibility of practical reasons for belief, which one might find an altogether too swift argument against this possibility.

Most importantly for our purposes, reasons to form beliefs about propositions seem value-driven in a relatively straightforward sense. Whether one has reason to form a belief about a particular subject matter depends on the value, whether intrinsic or derived, of having a belief about that subject matter. Clearly, the reasons can be grounded on a multitude of values. There is nothing to suggest that a single value, or category of values, should govern such reasons. They may be based on personal interest or curiosity. Arguably, my interest in road cycling gives me reason to form beliefs about the latest developments in Tour de France, while those without such interests have little or no reason to form such beliefs. In other cases, the reasons might be independent of personal interests, and even be universal in nature. Even if I have little personal interest in Danish politics, it is arguably my duty as a Danish citizen to exercise my democratic rights by voting, and thus to form beliefs about subject matters that are relevant to making an informed decision. At a more general level, we might all have a duty to form beliefs about the ways in which our actions affect others, the environment, or other common goods. The reasons may also be purely instrumental, as when we have reason to form the beliefs necessary to achieve goods of various sorts.

Another characteristic of reasons to form beliefs about propositions or subject matters is that they come in degrees of weight or importance. Although I have reason to form beliefs now about the latest developments in Tour de France, there might be other and more urgent matters I have more reason to form beliefs about. As such, reasons to form beliefs about propositions can be compared and weighed against other such reasons in the usual ways. In cases where I have equal reason to form beliefs 
about two alternative propositions or subject matters, and cannot form beliefs about both (I might have limited time to find out about the subject matters), I am rationally permitted to choose either of the two options. Reasons to form beliefs about propositions may also be weighed against practical reasons. It is not uncommon for reasons to form beliefs about subject matters to compete with practical reasons, since finding out about subject matters takes time and resources that could otherwise be devoted to other practical pursuits. In such cases, the value of forming the relevant beliefs must be weighed against the value of pursuing the competing practical pursuits. $^{14}$

These are all characteristics that set reasons to form or have beliefs about propositions apart from epistemic reasons to believe that some particular propositions is true. Whether I have epistemic reason to believe a particular proposition depends on the epistemic properties of that (potential) belief only, and these properties are entirely unaffected by the interest I may or may not have in that proposition, the moral or instrumental worth of believing the proposition, or any other such value giving property.

As such, the weighing of epistemic reasons with other epistemic reasons is entirely different in nature from the weighing of reasons to form beliefs about propositions or subject matters. In a paper not otherwise devoted to the nature of epistemic reasons, Jonathan Dancy observes the following:

One of the most striking differences between theoretical and practical rationality is that if I have sufficient practical reason for more than one option [...] I am rationally permitted to choose any of them, so long as they are roughly equally supported. By contrast, if I have sufficient and equally good reason for each of a set of alternative beliefs, I am not rationally permitted to choose any of them in preference to the others. (Dancy 2004: 95).

\footnotetext{
${ }^{14}$ For a detailed discussion of the way reasons to form beliefs may be weighed against each other, and against practical reasons, see Steglich-Petersen (2009).
} 
To illustrate the point I take Dancy to make, consider first a case in which you have sufficient practical reason for two alternative options that cannot both be pursued. For example, the fact that it would be fun to spend the afternoon playing crocket is a reason to do so; on the other hand, the fact that it would be pleasant to go swimming is a reason to pursue that option instead. In the absence of defeating reasons, both considerations provide sufficient reason, and they support the options with roughly equal weight. In that case, one is permitted to choose either. But consider now a case where you have roughly equal epistemic reason to hold each of two alternative beliefs, such that both cannot rationally be held at the same time. For simplicity, we might suppose that you have evidence for both $\mathrm{p}$ and not-p, that the two bodies of evidence support the truth of the relevant propositions to roughly the same degree, and that either body of evidence would have been sufficient to hold the relevant belief in the absence of any other evidence bearing on the matter. In this case, one is not permitted to hold either belief. The two epistemic reasons defeat each other, rather than make either option permissible. This difference between practical and epistemic reasons is easy to miss, because reasons of both kinds can outweigh reasons of the same kind, in case they support their relative options to a greater degree that the competing reasons. The difference only shows up in cases where there is (roughly) equal reason to pursue either of two alternative options, or hold either of two alternative beliefs.

With these initial characterisations in place, we can explore, in a loose and tentative way, the relationship between reasons for having beliefs about some proposition or subject matter, and epistemic reasons for believing that particular propositions are true. It has already been noted that reasons of neither kind entail 
reasons of the other. But we now need to explore how the two kinds of reasons rely upon each other in determining what one ought to believe.

First consider the situation in which $\mathrm{S}$ has an all things considered reason to form beliefs about some subject matter. Suppose, for example, that $\mathrm{S}$ is a registered voter, and that much is at stake in the election. In that case, it is plausible that $\mathrm{S}$ has all things considered reason to form beliefs about the policies of the Presidential candidates. This in itself is not sufficient to make it the case that $\mathrm{S}$ ought to believe particular propositions about the policies of the respective candidates, for example that one candidate is in favour of universal healthcare. If $\mathrm{S}$ has no evidence concerning that candidate's healthcare policy, it seems plausible that S shouldn't believe any particular propositions on that topic (or only extremely trivial ones, such as the proposition that it is the case of the candidate's healthcare policy that $\mathrm{S}$ has no evidence concerning it). So having all things considered reason to form a belief about $\mathrm{p}$ does not in itself entail that one ought to believe either that $\mathrm{p}$ or not-p. But suppose that $\mathrm{S}$ acquires sufficient evidence, and thus an epistemic reason to believe that the candidate indeed is in favour of universal healthcare. In that case, it seems that $\mathrm{S}$ ought to form the belief that the candidate is in favour of universal healthcare.

Consider next the case where $\mathrm{S}$ has no reason to form beliefs about some proposition or subject matter. Suppose, for example, that the subject matter is whether there is an even number of dust specks on S's desk. Let us also suppose that S has excellent evidence, and thus epistemic reason to believe in the sense defined, that there indeed is an even number of dust specks on his desk. In spite of this epistemic reason, it does not seem to be the case that $\mathrm{S}$ ought to form the belief that there is an even number of dust specks on her desk. It may be that S as a matter of fact cannot avoid forming that belief, since we are psychologically disposed to form beliefs that 
are supported by consciously considered evidence. But it is nonetheless not the case that S ought to form that belief. If S failed to form the belief, we wouldn't fault him or regard him as normatively worse off for that reason. ${ }^{15}$ We may regret that S's general psychological disposition did not make him form the belief, since more often than not, it is desirable to be disposed to form beliefs in accordance with the available evidence. But we would not regard $\mathrm{S}$ as having failed to do something he ought to have done. Nevertheless, S has epistemic reason to believe the relevant proposition. So one may have overall epistemic reason to believe that $\mathrm{p}$ without it being the case that one ought to believe that $\mathrm{p} .{ }^{16}$ If, on the other hand, a belief about the number of dust specks should become valuable for S (an eccentric billionaire might give him a prize for forming a belief about that proposition ${ }^{17}$ ), thus giving rise to an all things considered reason to form a belief as to whether the content is true, this, together with the epistemic reason, would mean that $\mathrm{S}$ ought to believe that there is an even number of dust specks on his desk.

So far, then, the following relationships hold. If $\mathrm{S}$ has epistemic reason to believe that $\mathrm{p}, \mathrm{S}$ is such that, if he has all things considered reason to form beliefs about or as to whether $\mathrm{p}$, then he ought to believe that $\mathrm{p}$. If the latter conditional is false (which it is just in case the antecedent is true and the consequent is false), it is also false that $\mathrm{S}$ has epistemic reason to believe that $\mathrm{p}$. In other words, if it is not the case of $\mathrm{S}$ that having a reason to form beliefs about $\mathrm{p}$ materially implies that he ought to believe that $\mathrm{p}$, we may deduce that $\mathrm{S}$ does not have epistemic reason to believe that p.

\footnotetext{
${ }^{15}$ For further arguments to the effect that one cannot derive a normative conclusion from the fact that we are psychologically disposed to form beliefs in accordance with our consciously considered evidence, see Steglich-Petersen (2006a) and Dretske (2000).

${ }^{16}$ For further defence of this claim, see Steglich-Petersen (2008b).

${ }^{17}$ Since the billionaire does not require you to adopt a belief that a particular proposition is true, but only a belief as to whether the proposition is true, this example does not raise problems concerning the possibility of practical reasons for belief.
} 
The same holds for reasons to form beliefs about or as to whether $\mathrm{p}$. If $\mathrm{S}$ has all things considered reason to form beliefs about $\mathrm{p}, \mathrm{S}$ is such that, if he has epistemic reason to believe that $\mathrm{p}, \mathrm{S}$ ought to believe that $\mathrm{p}$. If the latter conditional is false (which it is just in case the antecedent is true and the consequent is false), it is also false that $\mathrm{S}$ has reason for form beliefs about $\mathrm{p}$. In other words, if it is not the case of $\mathrm{S}$ that having epistemic reason to believe that $\mathrm{p}$ materially implies that he ought to believe that $\mathrm{p}$, we may deduce that $\mathrm{S}$ does not have all things considered reason to form beliefs about $\mathrm{p}$. These relationships can thus be summed up as follows (where ' $\mathrm{T}$ ' stands for 'belief that' and 'A' stands for 'belief about'):

(T) Necessarily, if S has epistemic reason to believe that $\mathrm{p}$, then [if $\mathrm{S}$ has all things considered reason to form a belief about $\mathrm{p}, \mathrm{S}$ ought to believe that $\mathrm{p}]$

(A) Necessarily, if S has all things considered reason to form a belief about $\mathrm{p}$, then [if $\mathrm{S}$ has epistemic reason to believe that $\mathrm{p}, \mathrm{S}$ ought to believe that $\mathrm{p}]^{18}$

It is important to make clear that these schemas are not intended as analyses or definitions of the respective kinds of reasons. The schemas merely state certain complex relationships between reasons to form beliefs about propositions, epistemic reasons to believe propositions, and whether an agent ought to form a particular belief. As such, the schemas are compatible with the truth of a number of other claims about the relationship between these three conditions, some of which may be stronger than the ones focused on here. As indicated by the above discussion, however, the schemas do describe what appear to be fundamental properties of these two kinds of

\footnotetext{
${ }^{18}$ Of course, in both schemas, the necessity operator attaches to the main connective only, and thus not to the embedded conditional. Part of the upshot of the above discussion is that reasons of neither kind ever on their own entail that one ought to form the relevant belief.
} 
reasons. Furthermore, the schemas are quite permissive in a number of ways. For one thing, they leave open the details as to what it takes to have a reason to form a belief about some subject matter, and what epistemic properties some potential belief that $p$ must have in order to make it the case that one has epistemic reason to believe that $\mathrm{p}$. Perhaps more importantly, the schemas are silent as to whether there could be nonepistemic reasons to believe that $\mathrm{p}$. I mentioned at the outset that I would simply assume in this paper that some version of evidentialism is true, but nothing in these schemas exclude that it could be the case that one ought to believe that $\mathrm{p}$ in the absence of an epistemic reason. As mentioned, I take it to be a separate problem to explain the exclusivity of epistemic reasons, and I have dealt with it elsewhere (see footnote 3).

Since this paper is primarily about epistemic reasons, I will now leave schema (A) aside, and focus on schema (T), stating a necessary conditional with a statement about epistemic reasons as the antecedent. This schema can be altered and qualified in various ways to take into account a number of subtleties. For example, one might find it plausible that the normative force of the reason one has to form beliefs about some subject matter carries over to the ought-statement concerning belief in a particular proposition, on the condition that one has epistemic reason for believing that proposition. For example, consider two mutually independent propositions $\mathrm{p}$ and $\mathrm{q}$, where $\mathrm{p}$ is of great significance and $\mathrm{q}$ is of lower significance to the believer, such that one has an all things considered reason to form a belief about $\mathrm{p}$ and a mere weak pro tanto reason to form a belief about q. Suppose further that one has evidence of identical strength regarding the truth of the two propositions, and thus equal epistemic reason to believe either. Despite the equally strong epistemic reasons, it seems that the ought-statement concerning belief that $\mathrm{p}$ should be stronger than that concerning 
belief that q. In particular, it seems that in the case of $p$, it is entailed that one ought to believe it, while in the case of $q$ it is merely entailed that one ought to believe it in the absence of opposing reasons (these differences are analogous to the explanation of all things considered reasons and pro tanto reasons set out in Section 2). So the force of the ought-statement concerning belief in particular propositions depends on the force of the reasons to form beliefs about those propositions, and not on the force of the epistemic reasons one has for believing those propositions. Indeed, it is doubtful whether epistemic reasons have normative 'force' or 'weight' in that sense at all. When we speak of the 'force' or 'weight' of epistemic reasons, we usually have in mind a different quality, namely the degree to which the evidence, which the epistemic reasons depend upon, confirms the relevant proposition. But this only affects the degree of belief one should adopt in that proposition, not the force of the ought-statement concerning the formation of the relevant belief. If this is plausible, the schema might be qualified in the following way, where the inserted parentheses indicate that the degree of belief one ought to adopt is determined by the epistemic reason, and the split of the schema into two, corresponding to pro tanto reasons and all things considered reasons respectively, indicates that the normative force of the ought-statement concerning belief in a particular proposition is determined by the reason one has to form beliefs about that proposition:

( $\mathrm{T}$ - all things considered)

Necessarily, if S has epistemic reason to believe that $\mathrm{p}$ (to degree $\mathrm{D}$ ), then [if $\mathrm{S}$ has all things considered reason to form a belief about $\mathrm{p}, \mathrm{S}$ ought to believe that $\mathrm{p}$ (to degree $\mathrm{D})]$. 
( $\mathrm{T}-$ pro tanto)

Necessarily, if S has epistemic reason to believe that $\mathrm{p}$ (to degree $\mathrm{D}$ ), then [if $\mathrm{S}$ has a pro tanto reason to form a belief about $\mathrm{p}$, then, in the absence of opposing reasons, $\mathrm{S}$ ought to believe that $\mathrm{p}$ (to degree $\mathrm{D})]$.

However, in the following I will ignore these qualifications of schema (T), and focus on the initial simple version of $(\mathrm{T})$ only. The important thing for our purposes is that the schema specifies a precise sense in which epistemic reasons for some belief are related to the value of having that belief. If reasons for forming beliefs about propositions are value-driven, then epistemic reasons are value-driven too, in the sense that they entail that one ought to believe particular propositions in the context of a value-driven reason only. Pointing out this dependence of epistemic reasons on values is a significant step towards solving the value problem for the teleological account of epistemic reasons. It is not in itself, however, sufficient. What is still missing is an explanation of why this dependence holds.

\section{A teleological explanation of the relationship}

The teleological explanation to be offered in this section is a version of the instrumentalist account of epistemic reasons. According to one influential version of this account, epistemic reasons are a species of standard instrumental reasons.

Roughly, $\mathrm{S}$ has instrumental reason to $\phi$ if and only if there is some aim that $\mathrm{S}$ has reason to pursue, and $\phi$-ing is the best available way (or a step in the best available 
way) of realising that aim. ${ }^{19}$ For example, if I have reason to go to London, and going to the airport is a step in the best available way of going to London, I have instrumental reason to go to the airport. The standard analogous instrumentalist explanation of epistemic reasons proceeds roughly as follows. First it is observed that forming a belief involves having a particular aim, for example that the belief is true or amounts to knowledge. ${ }^{20}$ So if $\mathrm{S}$ has reason to form a belief about $\mathrm{p}, \mathrm{S}$ has reason to pursue the aim involved with forming a belief about $\mathrm{p}$, i.e. believing the truth concerning $\mathrm{p}$, or coming to know whether $\mathrm{p}$, depending on the specific account. This means that one has instrumental reason to believe that $\mathrm{p}$ just in case one has reason to form a belief about $\mathrm{p}$, and believing $\mathrm{p}$ is the best way to realise the aim involved with forming such a belief. Finally, it is pointed out that the conditions under which believing $\mathrm{p}$ is instrumental or conducive to the aim involved with forming a belief about $\mathrm{p}$, coincide with the conditions under which one has epistemic reason to believe that $\mathrm{p}$, thus making it plausible to regard epistemic reasons as a special case of instrumental reasons.

As already pointed out, however, this simple instrumentalist explanation is flawed since epistemic reasons do not depend in such a straightforward sense on reasons for forming the relevant beliefs, and thus for adopting the putative aim involved with forming those beliefs. I can have an epistemic reason to believe that there is an even number of dust specks on my desk, regardless of whether I have

\footnotetext{
${ }^{19}$ Although this rough account will be sufficient for our purposes, the question of how to correctly understand instrumental reasons is a subtle and much debated issue. For representative strands of the recent debate, see Wallace (2001), Schroeder (2004), and Broome (2007).

${ }^{20} \mathrm{I}$ am ignoring here certain subtleties concerning how to best phrase the claim that beliefs have a constitutive aim. In particular, one has to ensure that the term 'belief' does not appear in the statement of such an aim, since the aim is part of what beliefs are supposed to consist of, thus making such a statement uninformative. One way of ensuring this would be state the aim in terms of the more general notion of 'acceptance'. For example, believing $\mathrm{p}$ might be identified with the attitude of accepting $\mathrm{p}$ with the aim of thereby accepting a truth. For more on this account, see Velleman (2000) and SteglichPetersen (2006a).
} 
reason to form a belief about that matter in the first place. So a straight assimilation between epistemic reasons and instrumental reasons is not available.

However, there is a different sense of instrumental reasons to which epistemic reasons might be assimilated instead. This is the purely hypothetical sense of instrumental reasons that we have to pursue hypothetical aims, regardless of whether or not we in fact have those aims, or have reason to pursue those aims. For example, regardless of whether I have reason to go to London, I am such that if I have reason to go to London, then I ought to go to the airport. Countless such conditional statements are true of each of us all the time, corresponding to all of the instrumental actions to hypothetical aims that are available to us. For each of the endless number of hypothetical aims I might adopt, there will be a number of available actions that are instrumental to that aim. Once again, we can characterise this kind of reasons in terms of a conditional statement (where 'HI' stands for 'hypothetical instrumental reason'):

(HI) Necessarily, if S has hypothetical instrumental reason to $\phi$ in pursuit of aim A, then [if S has all things considered reason to pursue aim A, S ought to $\phi$ ].

Once again, this conditional does not amount to an analysis or a definition of hypothetical instrumental reasons, but merely states an important relationship between such reasons, all things considered reasons, and ought-statements. A number of qualifications and comments are needed. The first concern the possibility of competing instrumental reasons to pursue the same aim. Often there will be several ways to achieve the same aim, so one cannot infer from the fact that there is instrumental reason for $\mathrm{S}$ to $\phi$ in order to achieve $\mathrm{A}$, to it being the case that $\mathrm{S}$ instrumentally ought to $\phi$, since there might be a stronger instrumental reason to $\psi$, if 
$\psi$-ing is an overall better way of achieving A. So in the above schema, ' $\mathrm{S}$ has hypothetical instrumental reason to $\phi$ in pursuit of aim A' should be understood as indicating an overall hypothetical instrumental reason, i.e. that $\phi$-ing is the best available way to pursue A. Under this assumption it might be observed that the normative force attaching to the consequent ought-statement carries over from the normative force of the reason for pursuing the relevant aim: if the reason for pursuing the relevant aim is a mere pro tanto reason, the consequent ought-statement should be qualified to state that $\mathrm{S}$ ought to $\phi$ in the absence of opposing reasons not to pursue aim A. Finally, a comment is needed to dispel any worries about the scope of the consequent ought in the embedded conditional. In discussions about instrumental rationality, i.e. the rationality of taking the means to one's aims, it is often assumed that instrumental rationality gives rise to wide-scope oughts, rather than a narrowscope ones. On the narrow-scope account, if S has some aim A, and $\phi$-ing is necessary in pursuing $\mathrm{A}, \mathrm{S}$ ought to $\phi$. But this has the counterintuitive result that one ought to take the means to aims that one does not have reason to pursue. For example, if an arsonist has the aim of burning down his neighbour's house, he ought to pour some gasoline on it if that is necessary to burn down the house. Proponents of the widescope account suggest instead that the central demand of instrumental rationality should be phrased in terms of an ought that takes the entire conditional as its scope, in the following way: S ought to ensure that if $\mathrm{S}$ has aim $\mathrm{A}$, and $\phi$-ing is necessary in pursuing A, S $\phi$ s. According to wide-scopers, this avoids the counterintuitive result since it is silent as to whether one should comply with it by giving up the aim, or by taking the means to it. Given this, however, it should be clear that none of these worries are relevant to the above schema concerning hypothetical instrumental reasons. In the schema, the embedded conditional moves from $\mathrm{S}$ having an all things 
considered reason to pursue $\mathrm{A}$, to it being the case that $\mathrm{S}$ ought to take the means. So it never demands that one take the means to an aim one does not have reason to pursue.

With this explication of hypothetical instrumental reasons in place, we can return to the issue of epistemic reasons. If we interpret reasons to form beliefs about propositions as reasons to pursue a certain aim involved with believing (for the present purposes we need only identify this as the aim of forming a belief as to whether some proposition is true), and interpret believing particular propositions as ways of pursuing that aim, such that one forms a belief in a particular proposition in order to form a belief about or as to whether that proposition is true, the above schema for hypothetical instrumental reasons (HI) is structurally identical to schema (T) describing the relationship between epistemic reasons to believe that $\mathrm{p}$, reasons to form beliefs about $\mathrm{p}$, and whether one ought to believe that $\mathrm{p}$. Both schemas state a conditional relationship between the obtainment of a certain kind of reason and the truth of another conditional, moving from the obtainment of a different kind of reason to an ought-statement. Furthermore, in both schemas, the normative force of the consequent ought-statement is carried over from the reason in the embedded conditional, and the content of what one ought to do is carried over from the reason on the left hand side of the overall conditional. This structural identity suggests that one possible explanation of the relationship outlined in Section 4 is that epistemic reasons are simply special cases of what we have called 'hypothetical instrumental reasons'. To be precise, they are instrumental reasons for believing particular propositions in pursuit of the hypothetical (i.e. present or non-present) aim of forming beliefs about those propositions. It is this fact that explains the special relationship between epistemic reasons, reasons to form beliefs about certain propositions, and 
ought-statements, explicated in the previous section. This claim obviously stands in need of further clarification. A helpful way of doing so will be to test it against a number of objections.

\section{Objections}

The perhaps most influential objection to standard instrumentalist accounts of epistemic reasons, is that it would make epistemic reasons hypothetical in a sense they are clearly not. As mentioned in the previous, on the standard version of the instrumentalist account, epistemic reasons depend on the contingent aims of the believer. In an influential discussion, Kelly has pointed out that epistemic reasons are not hypothetical in that sense. Most importantly, epistemic reasons are usually considered to be intersubjective in a way that they could not be if they depended on the particular aims of agents. When we offer evidence to someone, we take the evidence to provide epistemic reason for that person to believe a particular proposition, regardless of whether she happens to have the relevant cognitive goal (Kelly 2003, 621).

The present account avoids this objection in two distinct ways. First of all, it does not make what one ought to believe depend on the aims or desires of agents, but rather on the reasons agents have to form beliefs about certain propositions or subject matters. As mentioned above, it seems that such reasons are value-based in a relatively straightforward sense: whether one has reason to form beliefs about some subject matter depends on the value of doing so. I have left it open whether such reasons might be categorical in certain instances, but there is no principled reason why they couldn't be on the present account. Secondly, on the proposed account epistemic reasons are not hypothetical in the problematic sense that Kelly has in mind. 
Whether someone has epistemic reason to believe a particular proposition depends on the evidence available concerning the truth of that proposition. As such, epistemic reasons are intersubjective - providing evidence to someone is equivalent to providing that person with an epistemic reason, regardless of the particular aims and desires of that person. Epistemic reasons are hypothetical only in the sense that whether one ought to form a belief in accordance with them depends on an additional factor, namely whether one has reason to form beliefs about the relevant propositions in the first place. And it is fully compatible with the present account that these additional reasons might be categorical.

Another possible objection is that the present proposal downplays the normative significance of epistemic reasons to an implausible extent. The proposal would in effect assimilate epistemic reasons to the infinite number of conditional statements about instrumental reasons that are true of us all the time. For example, whether or not I have reason to go to London, it is true of me right now that if I have all things considered reason to go to London, then I ought to go to the airport. This conditional truth follows from the fact that going to the airport is necessary in order for me to go to London. Countless other such conditional statements are true of me at all times. It is true of me that if I have reason to call my mother, then I ought to turn on my phone, and so on ad infinitum. Can it really be true that epistemic reasons are as normatively insignificant as that?

But setting it up this way makes the situation seem worse than it really is. Two considerations should make it appear decidedly more palatable. First of all, if I did have a reason to go to London, it would be normatively significant that a necessary step for me to do so is to head out to the airport. The same goes for epistemic reasons, and we do have reason to form beliefs about a rather large number of propositions and 
subject matters. So very often, it is of normative significance to be such that if one has reason to form beliefs about some proposition, then one ought to believe that proposition. Secondly, it does seem true that we have much more evidence available than we have reason to respond to by forming the appropriate beliefs. If epistemic reasons are generated by evidence available to us, we have a large, perhaps infinite, number of epistemic reasons all the time, and far from all of them are about matters worth forming beliefs about. It would be absurd for an account of epistemic reasons to entail that we are at fault for failing to respond to all those epistemic reasons, so any account of epistemic reasons must be able to explain why we are quite justified in not caring about the vast majority of them. The proposed account does just that, by making the normative import of epistemic reasons depend in a systematic way on a different kind of value based reasons.

In this way, the account may also help to resolve a current dispute over the normative status of evidence. In his original criticism of instrumentalism about epistemic reasons, Kelly (2003) argued that the instrumentalist cannot explain how we can have epistemic reasons for believing propositions that we have neither reason nor desire to form beliefs about, such as propositions about the ending of a movie we are about to watch. Adam Leite (2007) has objected to this that we ought to distinguish between having epistemic reason to believe some proposition, and having evidence suggesting that proposition to be true. While having an epistemic reason is a normative property of some person, having evidence is a purely descriptive property. So having evidence doesn't necessarily imply having an epistemic reason. But in his reply to Leite, Kelly (2007) argues that there is no clear non-normative sense of evidence. ${ }^{21}$ As the argument goes, evidence cannot be understood save as something

\footnotetext{
${ }^{21}$ Kelly attributes this point to Jaegwon Kim (1988).
} 
that makes a difference to what one is justified in believing. Kelly even suggests that 'evidence' might be more or less synonymous with 'reason to believe', at least as long as this latter term is understood in the epistemic sense (2006). If that is correct, the instrumentalist cannot rely on a sharp distinction between those two terms in answering Kelly's initial challenge, as Leite has suggested. It seems, however, that the account proposed here can accommodate the intuition that evidence must be understood normative terms, and even that 'evidence' is synonymous with 'epistemic reason', without thereby committing to the view that having evidence requires that one form a belief in accordance with it. For suppose that we accept the equivalence between having evidence and having an epistemic reason. On the current account, none of these terms would then be understandable in non-normative terms, since they (necessarily) entail a conditional statement about what one ought to believe. But since the 'ought' in question is embedded in a conditional, Kelly's initial challenge is avoided. The embedded conditional can be true without the consequent oughtstatement of that conditional being true. One can thus have evidence, and therefore epistemic reason to believe some proposition, without it being the case that one ought to form a belief in that proposition, as in Kelly's problematic movie case.

A further possible objection is that the account fails to explain why one can be rationally unassailable in holding an evidentially supported belief in a proposition that one has no reason to have or form beliefs about in the first place. It seems, for example, that even if I have no reason to have or form a belief about the ending of the movie I am about to watch (even, in fact, if I have all things considered reason not to), if I inadvertently were to acquire evidence about the ending and form a belief accordingly, that belief would be rationally unassailable. The most plausible answer to this objection, I think, is to point out that even if the belief in question is 
unassailable in the sense that the believer cannot be blamed for having formed it, the belief is nonetheless regrettable. It is regrettable for someone to form a belief about the ending of a movie he or she is about to watch, especially if the enjoyment of the movie depends partly on not knowing how it ends. This point seems to generalise to all beliefs that we have reason not to form. We routinely withhold evidence from people because we judge that they have reason not to form the belief in question, and this seems a perfectly justifiable practice. So if the beliefs in question are 'rationally unassailable', this must be in a specific sense rather than tout court. But if that is the case, the present account can explain the rational unassailability of such beliefs in a perfectly straightforward way. On the present account, if S has epistemic reason to believe that $\mathrm{p}, \mathrm{S}$ is such that, if she has all things considered reason to form beliefs about $\mathrm{p}, \mathrm{S}$ ought to believe that $\mathrm{p}$. A belief can thus be rationally unassailable for $\mathrm{S}$ from an epistemic point of view (supported by epistemic reason, that is), without $\mathrm{S}$ being such that she ought to believe that $\mathrm{p}$.

\section{Conclusion}

I have proposed that epistemic reasons be regarded as a species of what I called hypothetical instrumental reasons. The arguments came in two stages. First it was argued that, necessarily, if S has epistemic reason to believe that $\mathrm{p}$, then $\mathrm{S}$ is such that if she has all things considered reason to form beliefs about $\mathrm{p}, \mathrm{S}$ ought to believe that p. It was then argued that this relationship between epistemic reasons, reasons to form beliefs about certain propositions, and normative statements about what a person ought to believe, could be explained by supposing that epistemic reasons are hypothetical instrumental reasons. The main virtue of this account is that it provides a sense in which epistemic reasons are teleological, or value based, without 
commitment to epistemic properties being valuable in a general sense, or to there being a sense in which every epistemically well-founded belief is valuable. In this way, the account avoids the perhaps most pertinent problem faced by teleological accounts in recent years, namely what I termed the 'value problem'. Furthermore, the account avoids problems typically associated with purely instrumentalist variants of the teleological account, since it avoids making epistemic reasons aim or desire dependent, while at the same time explaining why epistemic reasons do not in themselves require that a belief be formed. Needless to say, the account must be clarified and developed further before its merits can be assessed fully. But I hope to have shown that the teleological account may be more resilient than is often supposed. $^{22}$

\section{Biography}

Alston, W. (2005), Beyond Justification: Dimensions of Epistemic Evaluation, Ithaca, NY: Cornell University Press.

Bonjour, L. (1985), The Structure of Empirical Knowledge, Cambridge, Mass: Harvard University Press.

Broome, J. (2007), 'Wide or Narrow Scope?', Mind 116: 359-70.

Broome, J. (2004), 'Reasons', in Reason and Value: Themes from the Moral Philosophy of Joseph Raz, eds. R. J. Wallace, M. Smith, S. Scheffler and P. Pettit, 2855. Oxford: Oxford University Press.

\footnotetext{
${ }^{22}$ This paper was presented for audiences in Aarhus, Stockholm, Geneva, and at the annual meeting for the Philosophical Association of Southern Africa. For helpful comments and criticism, I wish to thank Carl Erik Kühl, Johanna Seibt, Raffaele Rodogno, Andrew Reisner, Jane Heal, Pascal Engel, Kathrin Glüer-Pagin, Peter Pagin, Jonas Olson, Ward Jones, Veli Mitova, Timothy Chan, Davide Fassio, Philipp Keller, Igor Douven, and two anonymous referees for Cambridge University Press.
} 
Dancy, J. (2004), 'Enticing Reasons', in Reason and Value: Themes from the Moral Philosophy of Joseph Raz, eds. R. J. Wallace, M. Smith, S. Scheffler and P. Pettit, 91118. Oxford: Oxford University Press.

Dretske, F. (2000), 'Norms, History, and the Constitution of the Mental', in his Perception, Knowledge, and Belief, 242-58. Cambridge: Cambridge University Press. Foley, R. (1987), The Theory of Epistemic Rationality, Cambridge, Mass.: Harvard University Press.

Goldman, A. (1999), Knowledge in a Social World, New York, NY.: Oxford University Press.

Grimm, S. (2008), 'Epistemic Normativity', in Epistemic Value, eds. A. Millar, A Haddock, and D. Pritchard, Oxford: Oxford University Press.

Kelly, T. (2007), 'Evidence and Normativity: A Reply to Leite', Philosophy and Phenomenological Research 75: 465-74.

Kelly, T. (2006), 'Evidence', Stanford Encyclopedia of Philosophy.

Kelly, T. (2003), 'Epistemic Rationality as Instrumental Rationality: A Critique', Philosophy and Phenomenological Research 66: 612-640.

Kim, J. (1988), 'What is Naturalized Epistemology?', Philosophical Perspectives 2: $381-405$

Lehrer, K. (1990), Theory of Knowledge, Boulder, Co.: Westview Press.

Leite, A. (2007), 'Epistemic Instrumentalism and Reasons for Belief: A Reply to Tom Kelly’s “Epistemic Rationality as Instrumental Rationality: A Critique”, Philosophy and Phenomenological Research 75: 456-64.

Lynch, M. (2004), True to Life: Why Truth Matters, Cambridge, Mass.: MIT Press. Pritchard, D. (2007), 'Recent Work on Epistemic Value', American Philosophical Quarterly 44: 85-110. 
Raz, J. (1986), The Morality of Freedom, Oxford: Oxford University Press.

Reisner, A. (2009), 'The Possibility of Pragmatic Reasons for Belief and the Wrong Kind of Reason Problem, Philosophical Studies 145: 257-72.

Reisner, A. (2008), 'Weighing Pragmatic and Evidential Reasons for Belief, Philosophical Studies 138: 17-27.

Scanlon, T.M. (1998), What We Owe to Each Other, Cambridge, Mass.: Harvard University Press.

Schroeder, M. (2004), 'The Scope of Instrumental Reason', Philosophical Perspectives 18: 337-64.

Shah, N. (2003), 'How Truth Governs Belief', Philosophical Review 112: 447-82.

Shah, N. and Velleman, D. (2005), 'Doxastic Deliberation', The Philosophical Review 114: 497-534.

Steglich-Petersen, A. (2009), 'Weighing the aim of belief', Philosophical Studies 145: $395-405$.

Steglich-Petersen, A. (2008a), 'Against Essential Normativity of the Mental', Philosophical Studies 140: 263-83.

Steglich-Petersen, A. (2008b), 'Does Doxastic Transparency Support Evidentialism?', Dialectica 62: 541-47.

Steglich-Petersen, A. (2006a), 'No Norm Needed: On the Aim of Belief', The Philosophical Quarterly 56: 499-516.

Steglich-Petersen, A. (2006b), 'Voluntarism and Transparent Deliberation', South African Journal of Philosophy 25: 171-76.

Velleman, D. (2000), The Possibility of Practical Reason, New York: Oxford University Press. 
Wallace, J. (2001), 'Normativity, Commitment, and Instrumental Reason', Philosophers Imprint 1: 1-26. 